\title{
GCU
}

Glasgow Caledonian

University

University for the Common Good

\section{Evaluating workplace trust as a construct of worker engagement in construction}

\author{
Lawani, Kenneth; Hare, Billy; Cameron, Iain
}

Published in:

Proceedings of the ICE - Management, Procurement and Law

DOI:

10.1680/jmapl.18.00034

Publication date:

2019

Document Version

Author accepted manuscript

Link to publication in ResearchOnline

Citation for published version (Harvard):

Lawani, K, Hare, B \& Cameron, I 2019, 'Evaluating workplace trust as a construct of worker engagement in construction', Proceedings of the ICE - Management, Procurement and Law, vol. 172, no. 3, pp. 125-134. https://doi.org/10.1680/jmapl.18.00034

\section{General rights}

Copyright and moral rights for the publications made accessible in the public portal are retained by the authors and/or other copyright owners and it is a condition of accessing publications that users recognise and abide by the legal requirements associated with these rights.

Take down policy

If you believe that this document breaches copyright please view our takedown policy at https://edshare.gcu.ac.uk/id/eprint/5179 for details of how to contact us. 
TITLE: EVALUATING WORKPLACE TRUST AS A CONSTRUCT OF WORKER ENGAGEMENT IN CONSTRUCTION

\section{AUTHORS:}

Kenneth Lawani ${ }^{1}$, Billy Hare ${ }^{1}$, \& lain Cameron ${ }^{1}$

${ }^{1}$ Department of Construction and Surveying, Glasgow Caledonian University, Cowcaddens Road, G4 OBA, UK

Dr Kenneth Lawani; Lecturer in Construction Project Management -

Kenneth.Lawani@gcu.ac.uk

Professor Billy Hare; Deputy Director of the Built Environment Asset Management (BEAM) Research Centre - B.Hare@gcu.ac.uk

Professor lain Cameron; Dean for the School of Computing, Engineering and Built Environment-1.Cameron@gcu.ac.uk 


\section{ABSTRACT}

This qualitative study developed trust themes: 'lack of trust, ability (skill, experience and competence), benevolence and company integrity' from interviews based on the perceptions of workers. It also developed a framework which was used for validating workplace trust and its influence on Occupational Safety and Health (OSH) practices. The phenomenological study adopted semi-structured interviews involving engaged workers until saturation. Additional 22 workers participated in validating the trust framework. Findings suggest that no worker perceived lack of trust within their organisations. Two workers perceived their own skill, knowledge and experience and that of other workers to work safely (as far as level 2); but do not perceive their organisation to genuinely care or exhibit elements of company integrity. Six workers perceived the presence of ability and genuine benevolence qualities within their workplace (as far as level 3). However, they identified lack of company integrity from their managers or supervisors, and that management often not do what they say regarding OSH practices at all times. Fourteen workers perceived the presence of ability, genuine benevolence and company integrity qualities (as far as level 4), and that the management adhere to a set of principles that they find acceptable and consistent. These workers also perceive their workplaces to have a strong and transparent organisational leadership and integrity. This study of workplace trust is part of a wider study involving the development of a Worker Engagement Maturity Model and a prototype mobile digital tool which would be useful for assessing existing workforce engagement towards improving OSH practices.

Keywords: Health \& safety, Management, Safety \& hazards

\section{INTRODUCTION}

The concept of worker engagement based on psychological conditions of personal engagement and disengagement at work states that employees can use different degrees of their selves physically, cognitively, and emotionally, while performing their roles (Kahn 1990). Research continues to highlight the advantages of developing a highly engaged workforce and therefore, many organisations are turning to enhancing levels of engagement within their influence (Wollard \& Shuck 2011).

However, it is suggested that it is only by measuring the performance of an activity in a business that such an activity could be managed and its performance further improved, (Salazar 2006). There is currently no recognised framework within the construction industry for evaluating the levels of workplace trust and workforce engagement for the improvement of Occupational Safety and Health (OSH) practices. Without the ability to assess workers' levels of trust and engagement, opportunities to improve construction OSH performance and the potential benefits on construction sites will be missing, (Lawani et al. 2018a). A key reference point for the development of worker engagement is the HSE Construction Division 'worker involvement/engagement' initiatives. This is seen as an explicit objective to encourage the industry to rise above the minimum legal requirement, moving towards 'best 
practice'. This is viewed as the involvement of every worker contributing to the improvement of health and safety.

Construction workers generally work on sites for short duration, and they tend to change physical location as well as institutional settings during the process of transferring to a new organisation and with a new workforce. As a result of this dynamic nature of activities that workers are engaged in, it is unusual for a construction worker to have absolute trust due to their involvement in an unstable working team. The literature on worker engagement has evolved from 'participation' (Lancaster et al. 2001), through 'involvement' (ECOTEC 2005), to 'engagement' (Cameron et al. 2006). This evolution reveals the increased interest in communication, knowledge sharing, and shared decision-making regarding OSH practices within the industry. It requires the commitment of management towards providing resources and effective communication, coupled with an open and 'no blame' environment in which problems are resolved through consultation and the use of shared knowledge and learning.

Previous studies relevant to construction worker engagement focuses more on workers spotting hazards and reporting injuries. Studies conducted by Gherardi et al. (1998); Bell \& Phelps (2001) and Shearn (2004) confirmed that this has led to a reduction in accidents. Cameron et al. (2006) and Hare et al. (2006) identified that the influence of management taking the initiative, providing resources, or encouraging feedback from workers about a range of matters have been the key contributors to these reductions. The increased trust, openness and commitment that these approaches engender could change the degree of engagement and the desire for workers to get more involved in OSH activities.

The HSG263 report (HSE 2015) identified worker engagement as a consultation process where management give information to the workforce (inclusive of supply chain and subcontractors) or employees and they in turn acquire feedback from them before making decisions. There are both legal and ethical requirements for management to engage with the construction workforce for the improvement of OSH e.g. Health and Safety (Consultation with Employees) Regulations 1996; The Management of Health and Safety at Work Regulations 1999.

Recent study has however conceptualised construction OSH engagement as: "A process where every worker on a construction site is motivated and empowered to participate in improving health and safety through meaningful discussions in advance of decisions being taken, influencing others, and is committed to sharing their experiences and knowledge; and managers positively encourage workers to identify and resolve health and safety problems in a culture of trust, leading to every worker on site benefiting from safe and healthy working conditions." (Lawani et al. 2017b; Lawani et al. 2017a). 
There is also an important element of reciprocity in trust (Scholefield 2000). For workers to be engaged and to reinforce their commitment within an organisation, the concept of reciprocity which underpins employer/employee contract has to be addressed. When an employer invests in worker's wellbeing, the workers feel valued and reciprocate directly with renewed employer loyalty and by working harder and more efficiently (Scholefield 2000). The role of trust is vital to engagement because if workers perceive the organisation as trustworthy, it is likely they will reciprocate by becoming more engaged in their work and be able to raise concerns without fear of reprisals. According to Ehin (2013), this means that for an organisation to succeed, its systems and practices need to have flexible capacity not only to support its organisational/business goals but also the physiological and mental needs of its members. Effective leadership and shared or distributed leadership create opportunities for enhanced worker morale; which in turn could facilitate improved worker effectiveness and performance, (Lawani et al. 2018a).

\section{RATIONALE FOR EVALUATING TRUST}

The aim of this paper is to evaluate workplace trust as a construct of worker engagement within the construction industry with the following objectives:

$\checkmark$ Evaluate workplace trust towards improving OSH engagement;

$\checkmark$ Develop a trust framework to measure levels and progress in engagement;

$\checkmark$ Validate the trust framework to assess levels of OSH engagement.

\section{TRUST IN RELATION TO OSH ENGAGEMENT}

This study remains consistent with already existent theories which are relevant to trust definition, i.e. a willingness to be vulnerable is maintained. Trust is a psychological state fundamental to the formation and sustenance of human relationships (Mayer et al. 1995; Clarke \& Payne 1997; Schoorman et al. 2007) and its importance in the workplace has been increasingly recognised (McAllister 1995; Bagraim \& Hime 2007; Colquitt \& Rodell 2011). The significance of trust has been closely aligned with areas such as communication and leadership (Atwater 1988), teamwork (Bews \& Martins 2002), and implementation of selfmanaged work teams (Lawler 1992); where working together involves interdependence on others in various ways to accomplish personal and organisational goals.

The construction workforce is getting increasingly diverse and the establishment of selfdirected teams and reliance on empowered workforce necessitates the need for the concept of trust, (Mayer et al. 1995). In spite of the growing importance of trust, research measuring the level of trust has witnessed diminishing trust among workers (Brown et al. 2015). Therefore, evaluating the levels of trust and engagement within the construction industry is both timely and significant.

Mayer et al. (1995) defined trust as the willingness to be vulnerable to another party when that party cannot be controlled or monitored. Therefore, trust can be considered as a 
psychological state that involves a decision-making process, affected by individual attitudes and cognitions, about an individual's willingness to accept vulnerability to another based on positive expectations of his or her actions in the future (Clarke \& Payne 1997; Mayer et al. 1995; McAllister 1995). Holste \& Fields (2010) view trust as affect-based which is grounded in mutual care and concern between workers, which Scholefield (2000) related to as an important element of reciprocity. In addition to risk, factors such as ability, genuine benevolence and company integrity are regarded as precursors of trust (Schoorman et al. 2007) and these will be explained subsequently in this paper. Schoorman et al's theory explains that perceptions of worker, supervisor/manager characteristics comprising trustworthiness are antecedents of trust. All three components contribute to the prediction of trust and mediate the effect of a performance appraisal system.

Some studies conducted within work organisations have shown positive relationship between trust and performance (Deluga 1995; Rich 1997), trust and empowerment (Lawani et al. 2018b); while others have indicated no relationship (Cropanzano et al. 1999; MacKenzie et al. 2001). According to existing theories, when workers lack trust in management and they are unwilling to be vulnerable to management; their cognitive resources will be preoccupied with non-productive issues, especially activities focused on self-protection or defensive behaviours (Ashforth \& Lee 1990). Thus, the manifestation of trust can be either active behaviours or the passive lack of engaging in self-protective behaviours. This has obvious implications for the management of $\mathrm{OSH}$.

\section{METHODOLOGY}

The phenomenological research approach, normally associated with philosophy and psychology describing the lived experiences of the individuals about a phenomenon, was adopted for this study (Creswell 2014; Marshall \& Rossman 2016; Creswell \& Poth 2017). It is an approach that describes the lived experiences of a concept or phenomenon for single or several individuals, (Creswell 2013). It usually involves conducting interviews with several workers regarding a phenomenon, such as their levels of trust within their workplace and engagement; see (Giorgi 2012). This type of description concludes in the core of the experiences for multiple workers that have experienced the phenomenon of workplace trust. This method was considered best fit based on the notion that the complexity of interactions between workers cannot be levelled to a statistical mean that overlooks their uniqueness for the study. The focus was on participants (construction frontline workers i.e. operatives and supervisors) and their perceptions of their workplace trust and experiences of being engaged in relation to $\mathrm{OSH}$ practices.

This study used an emerging qualitative approach that collected data within the 'natural workplace setting', which could be sensitive to the workers under study, and data analysis that was inductive by establishing patterns or themes, (Creswell 2013). To fully conceptualise and evaluate workplace trust, this study needed to understand issues of trust within the workplace from the workers but without building prejudiced ideas or assumptions as it goes 
against the phenomenological technique (i.e. bracketing technique). Therefore, adopting this technique meant consciously putting aside own beliefs and prior knowledge about the trust phenomenon under investigation preceding to and throughout the phenomenological investigation; see (Chan et al. 2013; LeVasseur 2003). This was necessary to avoid elements of bias, which could affect the output of this study.

This study developed these set of interview questions for assessing workplace trust as an independent variable relevant to worker engagement and specific to projects. These questions strictly required the participants' responses to focus on their experiences and perceptions specific to the current sites or projects. The main questions adopted for this study included but not limited to:

- Who on site do you think is competent when it comes to H\&S?

- Which workers on site do you think work to the same H\&S standards as you?

- How fair do you think you are treated?

- Why do you think management wants to keep you safe and healthy?

- How confident are you to raise H\&S issues with your managers or supervisors or coworkers?

- How would you consider the management in terms of doing what they say regarding $H \& S ?$

Whenever clarity was required during the interview process, the researcher asked the participants to give relevant examples to enhance the subject been discussed.

\section{SAMPLING}

A purposeful sampling strategy (Creswell \& Plano Clark 2017; Palinkas et al. 2015) for construction projects/sites and workers within mainland Britain was utilised by selecting from a pool of projects made available by the Steering Group, resulting in eight project sites.

The projects are: two different projects with Facilities Management, Consultancy, and Project Management Company; one house building company; one house and municipal building company; two Civil Engineering companies; one new homes and property development company and one Civil Engineering and tunnelling company all within mainland UK. The involvement of the projects was based on the perception of their management that they have an engaged workforce (their workers are engaged in OSH activities and that workers' opinions and recommendations are given due consideration and implementation). Phenomenological studies typically range from three to ten participants (Creswell 2014). As part of a wider study, an initial twenty-eight (28) in-depth semi-structured, face-to-face, non-leading and openended interviews was conducted with frontline workers until saturation (Charmaz 2014). This enabled the building of trust themes until no new information from further interview was necessary. The interviews lasted from 20 to 60 minutes, with each individual interview an average of 40 minutes of which workplace trust was part of the wider subject. 


\section{SEMI-STRUCTURED INTERVIEWS \& DATA COLLECTION}

Implementing a phenomenological inquiry involved a range of possibilities for data collection predetermined by either the type of interview or the use of nonnumeric data analysis, (Creswell 2014; Marshall \& Rossman 2016; Creswell \& Poth 2017).

This study focused on the meaning that frontline workers brought into the issue of workplace trust and not the meaning that the researcher brought into it. Therefore, the study was emergent, not firmly prescriptive and minor changes incorporated in the course of collecting data e.g. re-adapting the questions, and the number of frontline workers interviewed before attaining saturation. The interviews focused on the phenomenon of workplace trust based on the perception of the workers and these were audio recorded.

The emerging recurring keywords grouped into broad themes emanated from the initial semistructured interviews. Therefore, for the researchers to fully understand extant theories of trust, review of literature relevant to workers' trust and engagement were also conducted. The emergent themes which are the personal experiences of the workers were inductively developed with members of the steering group into a proposed framework by adopting the Delphi technique. This enabled developing the essence of experience from operatives and supervisors towards a proposed framework central to trust and workforce engagement.

The sequences of events were:

I. Conducting initial interviews with engaged workers until saturation. It is important to clarify that 'disengaged workers' were not deliberately asked from employers as this could lead to prejudice and discrimination within the workplace. The engaged workers are workers involved in $\mathrm{OSH}$ initiatives, contribute to $\mathrm{OSH}$ discussions, are proactive about OSH behaviours and influence their colleagues.

II. Steering Group endorsement of emergent themes useful for developing the trust framework

III. Thematic analysis with involvement of Steering Group using Delphi technique with the aim of achieving convergence of opinions (Hasson et al. 2000)

IV. Reviewing literature central to workplace trust and OSH engagement and their alignment with emergent themes

V. Validation of the framework with additional 22 workers (11 highly and 11 averagely engaged workers) was implemented. The study chose to work with the terms 'highly' and 'averagely' engaged workers within the following context. A highly engaged worker is someone who has won health and safety awards; (or) actively contributes to health and safety discussions, committees or initiatives; (or) a health and safety champion; (or) show enthusiasm for health and safety matters when you speak to them. An averagely engaged worker is any other worker that fulfils their work role or duties but needing support to develop in their OSH initiatives; health and safety discussions; supporting them to be pro-active about OSH behaviours; and enhancing their capability to influence their colleagues. 


\section{Final findings from validation of the framework.}

The study subsequently mapped the emerging themes and their alignment with extant literature relevant to workplace trust and worker engagement.

\section{DEVELOPING TRUST FRAMEWORK}

The study used thematic data analysis for the development of the trust framework; providing an understanding of how the workers perceived the phenomenon (Moustakas 1994; Given 2008). The study further developed clusters of meaning from these significant themes using Nvivo10 for evaluating, interpreting and explaining social phenomena (QSR International 2014). The emerging themes from the initial set of interviews were compared with existing literature to establish any form of alignment with extant theories found in the literature. This was necessary to establish if the key themes from the interviews had similarities with existing theories of trust to further strengthen the credibility of the framework. The classifications of these themes from the workforce interviews went through an iterative process with the expert focus groups using Delphi technique to achieve convergence of opinions; see (Hsu \& Sandford 2007; Hasson et al. 2000). The final classification of the themes from the interviews were developed into the current 'dartboard' framework useful for assessing the precursors of workplace trust dependent on engagement practices already existing within the workplace - lack of trust, ability, genuine benevolence and company integrity; see Figure 1.

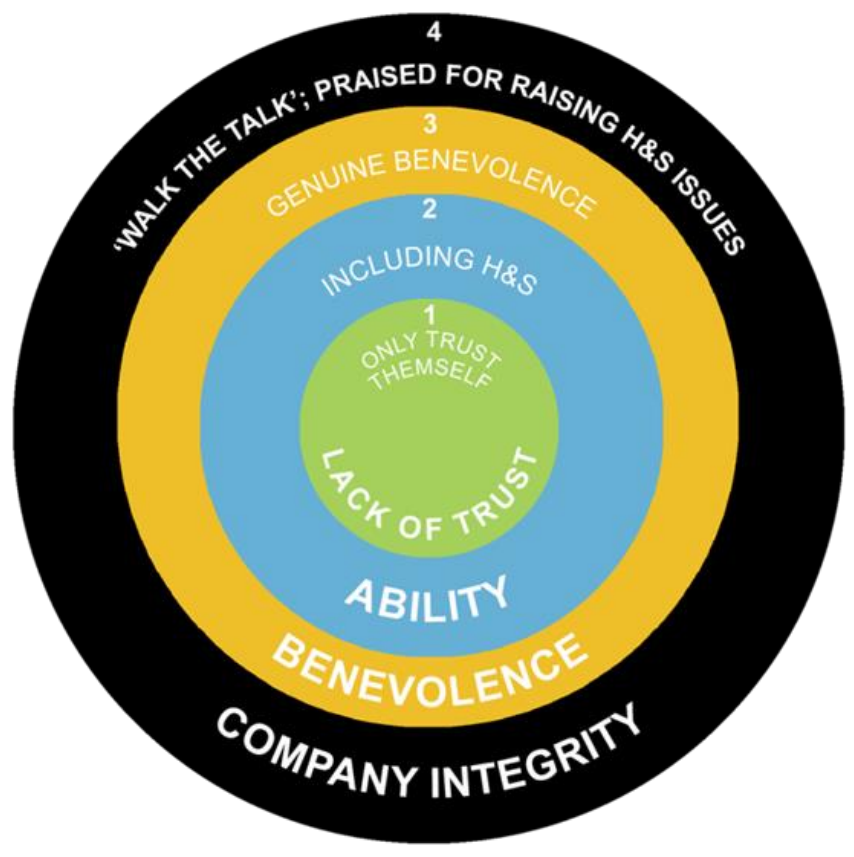

Figure 1: The Trust Framework

\section{LACK OF TRUST}

Lack of trust means the worker only trusts 'themselves'. In OSH terms, this translates to workers feeling no one else has their best interest at heart including co-workers and management. This level is regarded as the baseline or 'level one' of the framework with an assigned logical ratio of $25 \%$ along the trust continuum, see Table 1 . The higher a worker 
transcends along the continuum, the better their perception of trust within their workplace.

\section{ABILITY}

Ability refers to the group of skill, competencies, and characteristics that enable workers to have influence within some specific area (Colquitt \& Rodell 2011; Schoorman et al. 2007). Ability is the perception that a worker, supervisor or manager has skills and competencies in the domain of interest fundamental to workplace OSH practices. Holste \& Fields (2010) consider ability to be cognition-based trust which is grounded in co-worker reliability and competence. The important implication of ability as an antecedent of trust is that it creates a framework of trust that is domain specific (Lewicki et al. 1998). In OSH terms, this translates to workers having trust in his/her ability, i.e. skill, experience and competence and that of coworkers to work safely. This is regarded as 'level two' of the framework with an assigned logical ratio of $50 \%$ along the trust continuum, see Table 1 . Therefore, a worker that is classed as 'level 2 ' perceives their skill, experience, competence, and that of co-workers as paramount within their workplace.

\section{BENEVOLENCE}

Benevolence is the extent to which management is believed to want to do good to the worker, aside from egocentric profit motives (Schoorman et al. 2007; Colquitt \& Rodell 2011). Benevolence suggests that the management or manager have some specific attachment to the worker e.g. the relationship between a manager and a worker whereby the manager wants to help the worker even though he/she is not obliged to be helpful, with no extrinsic reward. The responses from the interviews addressed issues such as workers knowing that their co-workers and management wants them to go home safe every day; that management takes personal interest in each worker's OSH; and everyone acts in a respectful way towards workers. The workers also addressed issues regarding how management should treat and speak to workers just as they would expect to be treated; and how management makes the effort to ensure resources needed to do the jobs safely are available. Issues around management treating each worker as an individual rather than a group; management providing relevant information regarding training, reviews or job specifications so workers know the expectations; and management showing personal concern for workers' safety and well-being were identified.

Benevolence therefore can be described as the perception of a positive intent (quality of a relationship) of the management or manager toward the workers (Lawani et al. 2018a), and it is an antecedent of trust in a long-term relationship which also include motives. Holste \& Fields (2010) consider benevolence as affect-based trust which is grounded in mutual care and concern between workers. In OSH terms, benevolence relates to the extent a manager genuinely cares for the wellbeing of their workers, beyond mere employment obligations. This is regarded as 'level three' of the framework with an assigned logical ratio of $75 \%$ along the trust continuum, see Table 1. A worker that perceives 'ability' and 'benevolence' as paramount within their workplace is classed as 'level 3'. 


\section{COMPANY INTEGRITY}

Company integrity relates to how a company treats their workers regarding occupational health and safety, for instance when reporting concerns. The responses from the initial interviews related to issues such as the need for management to put workers OSH above everything else; the organisation making decisions with workers wellbeing in mind rather than just for the good of the business; the company behaving and acting in the same way to all workers; management recognising good performance and giving feedback on workers' performance; management recognising safe behaviours; management responding to workers concerns and discussing actions with workers; and managers giving clear expectations when it comes to health and safety. The relationship between integrity and trust involves the worker's perception that the manager/management adheres to a set of acceptable principles (Schoorman et al. 2007; Colquitt \& Rodell, 2011). In OSH terms, this is when the worker feels confident and perceives that raising any OSH concerns will be praised but not punished; there is mutual respect; that their supervisor/manager deals with them honestly and the management is approachable. This is classed as 'level four' of the framework with an assigned logical ratio of $100 \%$ along the trust continuum, see Table 1 . Workers with the perception of workplace ability; genuine benevolence and company integrity are those that could have some impact on decision-making within and beyond the site gate.

\section{Table 1: Antecedents and levels of trust}

\begin{tabular}{llll}
\hline Levels & $\begin{array}{l}\text { Ratio } \\
\mathbf{( \% )}\end{array}$ & $\begin{array}{l}\text { Antecedents of } \\
\text { Trust } \\
\text { Lack of Trust }\end{array}$ & $\begin{array}{l}\text { Requisite markers } \\
\text { Absence of ability; benevolence and company integrity. } \\
\text { Worker only trusts him/herself (i.e. personal) }\end{array}$ \\
$\mathbf{2 5}$ & $\mathbf{5 0}$ & Ability & $\begin{array}{l}\text { Trust in his/her and others skills, experience, and competence } \\
\text { to work safely and without problems (i.e. co-worker) } \\
\text { Genuine concern, manager cares about worker; } 2 \text {-way } \\
\text { relationship; loyalty; just culture (i.e. manager) } \\
\text { Confident that raising H\&S concerns will be praised; honesty; } \\
\text { do what they say; management approachable and respected; } \\
\text { fairness; feedback on performance (i.e. company) }\end{array}$ \\
\hline
\end{tabular}

The interviews suggested that ability is an important concept, as are integrity and benevolence. Although the conceptual interpretations between benevolence and integrity are somewhat equivocal, it could however be concluded that all three concepts are theoretically different based on the themes that emerged from the interviews. However, they all have an additive quality in determining the level of trust as shown in Table 1 and Figure 1. Lewicki et al. (1998) argued that trust and distrust (lack of trust) are separate dimensions and not the opposite ends of a single continuum. However, Schoorman et al. (2007) is of the opinion that trust and distrust (lack of trust) are the opposite ends of the same continuum and the evolution of trust is dependent on the level of interaction amongst workers. The definition of trust which is based on willingness to take risk (to be vulnerable) in a relationship 
- means that at the lowest level of trust, one would take no risks at all due to lack of skill, competence and experience (ability).

\section{VALIDATION, FINDINGS \& DISCUSSION}

The findings, final validation and discussion focused on these four themes used for developing the framework: - lack of trust; ability; benevolence; and company integrity. Another set of 22 interviews were carried out to validate these themes based on the developed framework. Findings from the validation exercise suggests that none of the 22 workers perceived lack of trust within their organisations; see Table 1 (level 1; ratio 25\%). Two workers perceived their own skill, knowledge and experience (ability) and that of other workers to work safely (as far as level 2; ratio $50 \%$ ) but they do not percieve their organisation to genuinely care neither do they perceive some elements of company integrity. Although these two workers have the requisite ability including $\mathrm{OSH}$ initiatives, they are however not considered to be fully engaged within their workplace. Six workers perceived the presence of ability and genuine benevolence qualities within their workplace (as far as level 3; ratio 75\%), while 14 workers perceived the presence of ability, benevolence and company integrity qualities (as far as level 4 ; ratio $100 \%$ ). The validation of the framework focused on the perception of the workers exemplified within their current workplace in relation to trust, engagement and OSH practices. Therefore, the findings identified from the trust framework are specific to the projects and sites used for the validation exercise.

\section{LACK OF TRUST}

Generally, a workplace with lack of trust (the worker only trusts 'themselves') could potentially lead to some level of surveillance or monitoring of work progress by the supervisors or managers. When workers perceive that they are frequently monitored, there is that tendency of the worker interpreting the manager or supervisor's observation as exemplifying some levels of suspicion or incompetence. The 22 workers that participated in the validation of the trust framework did not perceive signs of lack of trust within the current projects or organisation or from their management. If workers however perceive elements of lack of trust within their organisation or from their management, there is that tendency for the worker to react in reprisal e.g. by cutting corners; taking risks or by betraying the supervisor whenever the opportunity arises.

\section{ABILITY}

The result from the validation suggests that the skill, experience and competence (ability) required by workers to perform their tasks safely was highly perceived to be essential by the entire participants involved in the validation exercise. The workers agreed that within their current workplaces, they are competent enough to embark on their tasks with focus on OSH initiatives: 
"Most of the boys are pretty competent, [Company name] are looking out for you so you can't step out of line because they will go on your case."

"I'll say we're all good, H\&S is in the hands of the individual; we all make sure we work safely within one another."

"I feel we all have years of experience and knowledge to work safely on this site."

The validation however revealed that only two workers go as far as level 2 along the trust continuum with no progress beyond. This is based on their perceptions of their ability and the ability of other workers from the interviews. Although both workers displayed the requisite skill, experience and competence to accomplish their tasks safely; they did not perceive any form of genuine benevolence from the management neither do they perceive their organisations to demonstrate some form of company integrity. The two workers indicated that their organisation and management however recognised the importance of their 'ability' because if anything goes wrong in terms of H\&S, the company will face legal consequences.

\section{BENEVOLENCE}

When workers perceive evidence of ability and genuine benevolence amongst other workers, managers and management, they are considered to go as far as level 3 along the trust continuum. Based on the findings from the benevolence theme, qualities such as loyalty, openness, approachability, caring, supportiveness, and demonstration of concern towards workers were identified from the interviews:

"In terms of the professionals we are all very competent, I am very well and fairly treated. Management wants to keep me safe and healthy because they know my value. Management do not do as they say, not all the time, I would imagine things change and objectives change therefore their grand ideas change."

"I think everyone here is competent, I haven't seen anyone and think they shouldn't be doing that. Everyone on site works to the same standard; I am a new start and for me I am still finding my feet, there's not been any issue. They've sent me to other places for induction which seem to be an encouraging thing. Management seems much more approachable than what I was used to in my previous job."

The validation exercise identified that six (6) workers perceived functional elements of both ability and genuine benevolence from their management and within their workplace. However, the perception of their workplace did not go as far as showing elements of confidence in terms of company integrity with their managers or supervisors neither do they feel that the management often do what they say regarding $\mathrm{OSH}$ at all time.

All six workers identified that experience and competence were important in their successful performance in terms of OSH practices and that every worker tends to work to the same standard. They also indicated that their management or organisation tend to treat them very 
fairly within their workplace e.g. sending them on training courses which some consider as very encouraging, providing adequate resources and that management were overall, very approachable. Two of the six workers however perceive that the management care more about them to protect the company image and for insurance purposes rather than "genuinely focusing on the man".

\section{COMPANY INTEGRITY}

When workers perceive evidence of ability, genuine benevolence and company integrity amongst co-workers, managers and management, they go as far as level four because they fulfil all the requirements along the trust continuum. Company integrity is the relational demonstration of comprehensive moral and ethical principles within the workplace between management and workers. The concept of integrity is based on the interplay of the workers' perception that the management, managers or supervisors adheres to a set of principles that workers find acceptable and consistent:

"Everybody is competent because they are all briefed and trained; young lads are always sent along with experienced man to work alongside them. I am treated as fair as I could really ask for to be honest; any issues I have are always answered; I have no problem at all in raising anything. Management do what they say all the time, [Senior Management name] was here two weeks ago when we did the H\&S thing, and said anyone has within their rights to stop the job if they think it's not being done safely."

"Very important to have a very good knowledge of H\&S with our work, everybody with regards to the job I do have a good knowledge. My first job with [Company name] and my first tunnelling job, a lot different to what I am used to but I have adapted quickly; all of them I worked with were very welcoming when I started on this job. I have always been treated pretty fairly. They want everybody to go home safely at the end of the day. Everybody is different and you don't get into trouble for raising H\&S issue."

These implies that the workers perceive the managers or supervisors to demonstrate characteristics that show consistency, discreetness, fairness, promise fulfilment, reliability, openness, honesty, and just in decision-making that could impact job outcomes, (Conchie et al. 2013). The validation interview identified 14 workers with the perception of such qualities that matches the benchmark for ability, benevolence and company integrity within the trust framework. These workers were classed as those displaying high levels of trust (level 4) based on their perception of their workplaces to have a strong and transparent organisational leadership and organisational integrity (Tharaldsen et al. 2010; Conchie et al. 2013). The workers identified that experience, training and competence are all important and that young and inexperienced workers would always have to work alongside an experienced tradesman as a mentor. The workers perceive they are treated fairly within their workplace; they are able to raise H\&S issues without reprisal and management genuinely listen and care about their needs. The workers also acknowledged that management often tend to follow through 
what they say most of the time regarding H\&S and workers wellbeing. Although there are legal requirements in place on the part of the employer, the workers identified that they feel the main driver for their employers to look after their H\&S is because they genuinely care and respect them as individuals.

Also, the workers identified they are confident to raise H\&S issues with their managers or supervisors although they did identify that when the work program is running smoothly, H\&S issues tends to become of less priority and take the back seat. Overall, the workers perceive it is their responsibility to execute their task safely and go home safely and it is in the interest of the company to provide, care and keep them safe to avoid negative record with the HSE and for future bidding for other jobs.

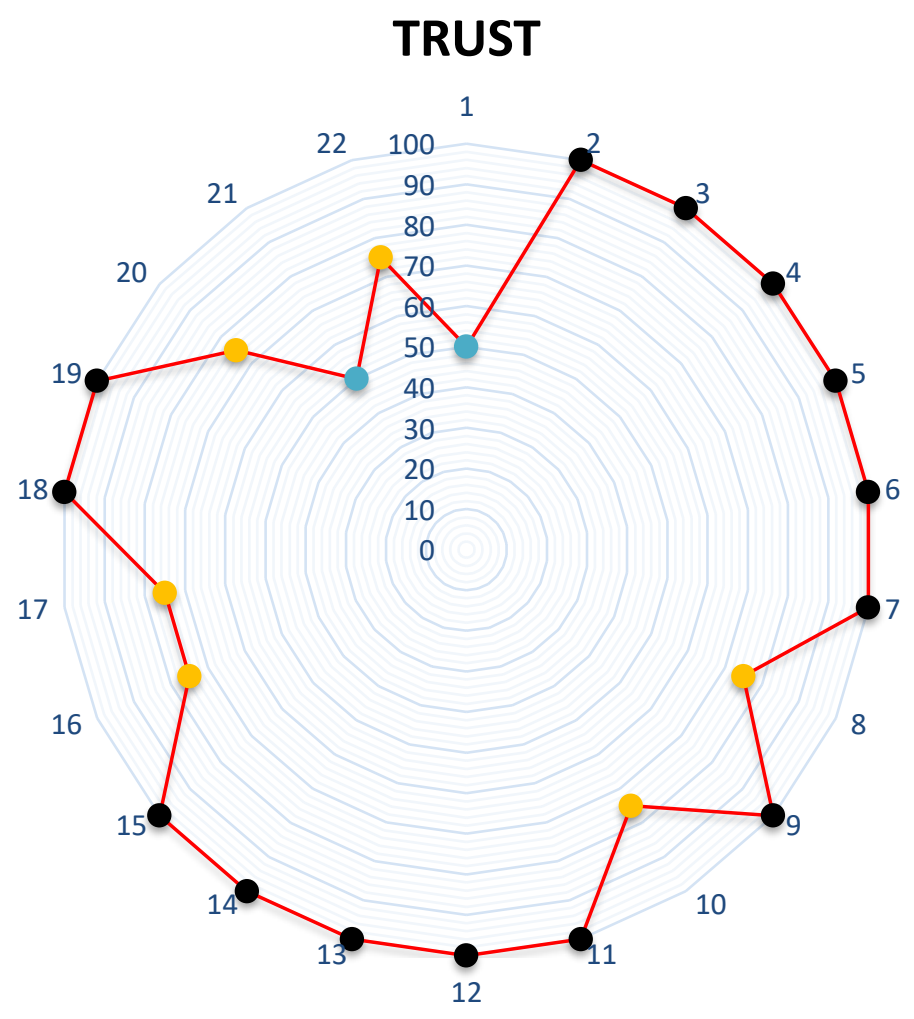

LACK OF TRUST

ABILITY

BENEVOLENCE

COMPANY INTEGRITY

\section{Figure 2: Results of trust validation reflecting the trust framework}

The findings from this study builds on the concept that ability (skill, experience and competence) is an important component in the domain of trust, so also are genuine benevolence and company integrity. The practical and conceptual understanding of trust and the differences of these antecedents have led to the conclusion that ability, genuine benevolence and company integrity are separate as identified by Mayer et al. (1995); Mayer 
\& Gavin (2005); and Schoorman et al. (2007). Therefore, this study considers lack of trust, ability, genuine benevolence and company integrity as a continuum of trust because they have a cumulative effect in determining the levels of trust relevant to OSH practices, see (Schoorman et al. 2007). The validation exercise shows that the extent to which the workers are willing to ascribe good intentions, have confidence in the words and actions of other workers, and trust for their organisation/company depends on their perceptions of their workplaces. An understanding of workplace trust and OSH practices could probably facilitate engagement and collaboration between workers, their organisations and management (Tharaldsen et al. 2010; Conchie et al. 2013). However, workplace trust, engagement and acceptable OSH practices can often be lacking in many construction sites for various reasons.

Despite the growing importance of trust, there are institutions that measure trust and have witnessed diminishing trust among their workers. However, the validation of the trust framework clearly suggest that workers involved in this study demonstrated a relatively confident level of trust amongst co-workers; trust for their organisations/management and this is founded on their perceptions of their workplace. The validation also suggested that lack of trust could potentially develop when management are unable to follow through on their promises and trust will certainly improve when they do follow through. Lack of trust could develop when managers or supervisors claim to embrace certain values but act in a manner at odds with them, and trust could develop as management consistently act in alignment with the values they say matters to them and the workers. For management and workers to earn trust, it would take consistency of words and actions which could take time to fully mature.

The findings also suggest that workers that have confidence in the company integrity within their workplaces most likely experience fairness and just-culture without the influence of authoritarian leadership see (Conchie et al. 2013). However, it is important that managerial incompetence related to the integrity of the management could possibly result in credibility gap that could potentially affect the perception of the levels of trust within an organisation.

Judgment of ability and company integrity forms relatively quickly in the course of a working relationship; however, benevolence judgment tends to take more time (Scholefield 2000; Schoorman et al. 2007). It does indicate that the development and sustenance of trust in the management can considerably lead to competitive advantage and safety performance, see (Tharaldsen et al. 2010). The validation exercise based on the perceptions of workers incorporates lack of trust, ability, genuine benevolence, and company integrity as mechanism for assessing trust within the workplace. It seems plausible therefore to assume that nurturing higher levels of trust would be a worthwhile goal for workers, supervisors, managers and organisations to pursue.

Research on workplace trust has also been associated with increased levels of organisational performance, but this mechanism and its effect have been less clear as there is no credible 
evidence that the new interest in trust has translated into higher trust levels in the workplace (Schoorman et al. 2007). However, the findings from this study suggests that the relationship between trust, engagement and safety performance may operate primarily through workers engaging in discretionary behaviour, i.e. positive reinforcement produces more positive behaviour and this could be achieved by tapping into an employee's discretionary effort, see (Fleming \& Lardner 2002). This is probably why 20 out of 22 workers that participated in the validation exercise perceived a high level of trust (as far as levels $3 \& 4$ ) with fellow workers, supervisors, managers and management within their workplaces (i.e. perception of workplace ability, genuine benevolence and company integrity).

It is important to recognise that project-wide engagement is one of the key benefits of the new Occupational Health and Safety Management Systems (ISO 45001) standard. The standard recognises the value of workforce engagement in the development of better OSH practices. Therefore, higher levels of workplace trust could potentially encourage workers to actively engage in the development, planning, implementation and continual improvement of the health and safety management system and worker engagement practices.

\section{CONCLUSIONS}

The four themes of workplace trust as a construct of worker engagement was developed to evaluate the perception of workers. These four themes could additively combine in determining the levels of trust and engagement of workers over time. The culture of an organisation could significantly have an impact on the trust levels that exists within a workplace. These findings could extend to work teams and organisational levels suggesting the importance of workers trusting each other and their organisations. It suggests that trust between workers and trust for the organisation is the extent to which the workers are willing to ascribe good intentions and have confidence in the words and actions of other workers and their employers.

The ability of workers to perform tasks with skill, experience and competence rated very highly with all the 22 workers involved in the validation exercise. This signifies that workers that participated in this study were engaged and competent enough to embark on their tasks with OSH initiatives as priority. The validation suggests that workers demonstrated absolute level of trust amongst co-workers in terms of their skill, experience and competence.

The study also suggests that some workers perceived functional elements of both 'ability' and 'genuine benevolence' from workers and management. However, some of their comments did not demonstrate absolute confidence regarding their managers or supervisors neither do they feel that the management often do what they say ('walk the talk') regarding OSH at all times.

The trust framework for assessing levels of trust is instrumental for management, managers and supervisors for evaluating workplace trust relevant to OSH practices. Lack of trust could 
potentially be cultivated when managers or supervisors do not follow through on their promises and trust develops when promises is fulfilled. Therefore, workplace trust could be improved as people consistently act in alignment with the values they say matters to them; and for management and the workforce (managers and supervisors) to earn trust, it takes consistency of words and actions over time.

\section{LIMITATIONS OF THIS STUDY}

This study involved workers, projects and organisations across mainland Britain. A purposeful sampling strategy was adopted for gaining access to organisations with construction sites, projects and workers with already existent workforce engagement practices. Successive study will require more projects to enable more in-depth cross-sectional analysis across individual projects, organisations and workers.

The ranking exercise for developing the trust framework (using the themes) was developed by implementing three phases of iterations using the Delphi technique. This process was slow in terms of the frequency of timely responses, tedious for the Steering Group members that participated and somewhat complicated which could become a potential threat to successful implementation. However, the aim of fulfilling the inter-rater requirements regarding consensus for the trust themes was still achieved. A well-motivated Steering Group is required for future success.

\section{RECOMMENDATIONS AND CONTRIBUTIONS FOR INDUSTRY PRACTICE}

A number of contractors involved in the study have already requested the use of this framework with its associated themes for assessing and benchmarking workplace levels of trust and OSH practices on their sites and projects relevant to their own established worker engagement practices. The recommendation is that other industries adopt the trust framework for benchmarking and improving engagement practices, particularly those with extensive industrialised workplaces and/or high-risk environments. The weightings of $25 \%$ for each of the four levels were arbitrary and not subjected to any further testing. The study of workplace trust is part of a wider study involving the development of a Worker Engagement Maturity Model and development of a prototype mobile digital application that would be useful for assessing workforce engagement. This digital tool would be useful for OSH practitioners to evaluate and benchmark workers' maturity levels within their workplace towards improving OSH practices in construction. This assessment tool is also hyperlinked to existing HSE Leadership and Worker Involvement Toolkit (LWIT) and other available OSH guidance documents to improve OSH practices.

\section{REFERENCES}

Ashforth, B. E. \& Lee, R. T., 1990. Defensive behaviour in organizations: A preliminary model. Human Relations, Volume 43, p. 621-648. 
Atwater, L. E., 1988. The relative importance of situational and individual variables in predicting leader behavior. Group and Organization Studies, Volume 13, pp. 290-310.

Bagraim, J. J. \& Hime, P., 2007. The dimensionality of workplace interpersonal trust and its relationship to workplace affective commitment;. SA Journal of Industrial Psychology, 33(3), pp. 43-48.

Bell, J. \& Phelps, C., 2001. Employee Involvement in Health and Safety: Some Examples of Good Practice, Broad Lane, Sheffield: HSL.

Bews, N. \& Martins, N., 2002. An evaluation of the facilitators of trustworthiness. South African Journal of Industrial Psychology, 28(4), pp. 14-19.

Brown, S., Gray, D., McHardy, J. \& Taylor, K., 2015. Employee trust and workplace performance. Journal of Economic Behaviour \& Organization, Volume 361-378, p. 116.

Cameron, I., Hare, B., Duff, R. \& Maloney, W., 2006. An Investigation into Approaches to Worker Engagement, London: HSE.

Chan, Z. C., Fung, Y.-I. \& Chien, W.-t., 2013. Bracketing in Phenomenology: Only Undertaken in the Data Collection and Analysis Process?. The Qualitative Report, 18(30), pp. 1-9.

Charmaz, K., 2014. Constructing grounded theory: Introducing qualitative methods. 2 nd ed. London: Sage Publications.

Clarke, M. C. \& Payne, R. L., 1997. The nature and structure of workers' trust in management. Journal of Organisational Behaviour, Volume 18, pp. 205-224.

Colquitt, J. A. \& Rodell, J. B., 2011. Justice, Trust, and Trustworthiness: A Longitudinal Analysis Integrating Three Theoretical Perspectives. Academy of Management Journal, 54(6), pp. 1183-1206.

Conchie, S. M., Moon, S. \& Duncan, M., 2013. Supervisors' engagement in safety leadership: Factors that help and hinder. Safety Science, Volume 51, pp. 109-117.

Creswell, J. W., 2013. Qualitative Inquiry and Research Design: Choosing Among Five Approaches. 3rd ed. Los Angeles: Sage Publications.

Creswell, J. W., 2014. Research Design: Qualitative, Quantitative, and Mixed Methods Approaches. 4th ed. Thousand Oaks, California: Sage .

Creswell, J. W. \& Plano Clark, V. L., 2017. Designing and Conducting Mixed Methods Research. 3rd ed. Thousan Oaks, CA: Sage Publications.

Creswell, J. W. \& Poth, C. N., 2017. Qualitative Inquiry and Research design: Choosing among five approaches. 4th ed. Thousand Oaks, California: Sage Publications.

Cropanzano, R., Prehar, C. \& Chen, P., 1999. Using social exchange theory to distinguish procedural from interactional justice. Group and Organization Management, Volume 27, p. 324-351. 
Deluga, R. J., 1995. The relation between trust in the supervisor and subordinate organizational citizenship behaviour. Military Psychology, Volume 7, p. 1-16.

ECOTEC, 2005. Obstacles preventing worker involvement in health and safety, London: HSE.

Ehin, C., 2013. Can people really be managed. International Journal of Commerce and Management, 23(3), pp. 184-203.

Fleming, M. \& Lardner, R., 2002. Strategies to promote safe behaviour as part of a health and safety management system, Norwich: Health and Safety Executive.

Gherardi, S., Nicolini, D. \& Odella, F., 1998. What do you mean by safety? Conflicting perspectives on accident causation and safety management in a construction firm. Contingencies and Crisis Management, 6(4), pp. 202-213.

Giorgi, A., 2012. The Descriptive Phenomenological Psychological Method. Journal of Phenomenological Psychology, 43(1), pp. 3-12.

Given, L. M., 2008. The SAGE Encyclopedia of Qualitative Research Methods. Thousand Oaks, CA: SAGE Publications Ltd.

Hare, B., Cameron, I. \& Duff, R., 2006. Exploring the integration of health and safety with pre-construction planning. Engineering, Construction and Architectural Management, 13(5), pp. 438-450.

Hasson, F., Keeney, S. \& McKenna, H., 2000. Research guidelines for the Delphi survey technique. Journal of Advanced Nursing, 32(4), pp. 1008-1015.

Holste, S. J. \& Fields, D., 2010. Trust and tacit knowledge sharing and use. Journal of Knowledge Management, 14(1), pp. 128-140.

HSE, 2015. Involving your workforce in health and safety - Guidance for all workplaces, Suffolk: HSE.

Hsu, C.-C. \& Sandford, B. A., 2007. The Delphi Technique: Making Sense of Consensus. Practical Assessment, Research \& Evaluation, 12(10), pp. 1-8.

Kahn, W. A., 1990. Psychological conditions of personal engagement and disengagement at work. The Academy of Management Journal, Volume 33, pp. 692-724.

Lancaster, R., McAllister, I. \& Alder, A., 2001. Establishing effective communications and participation in the construction sector, London: Entec report for Health and Safety Executive.

Lawani, K., Hare, B. \& Cameron, I., 2017a. Developing a worker engagement maturity model for improving occupational safety and health $(\mathrm{OSH})$ in construction. Cape Town, Central University of Technology, Free State, pp. 615-624.

Lawani, K., Hare, B. \& Cameron, I., 2017b. Developing a worker engagement maturity model for improving occupational safety and health $(\mathrm{OSH})$ in construction. Journal of Construction Project Management and Innovation, 7(2), pp. 2116-2126. 
Lawani, K., Hare, B. \& Cameron, I., 2018b. Empowerment as a Construct of Worker Engagement and Wellbeing. Salvador, Brazil, Marketing Aumentado, pp. 388-396.

Lawani, K., Hare, B., Cameron, I. \& Dick, S., 2018a. Management's 'Genuine Benevolence' \& Worker Commitment to Health \& Safety - A Qualitative Study. Salvador, Bahia, Marketing Aumentado, pp. 318-326.

Lawler, E., 1992. The ultimate advantage: Creating the high-involvement organization. San Francisco: Jossey-Bass.

LeVasseur, J. J., 2003. The problem of bracketing in phenomenology. Qualitative Health Research, 13(3), pp. 408-420.

Lewicki, R. J., McAllister, D. J. \& Bies, R. J., 1998. Lewicki, R. J., McAllister, D. J., \& Bies, R. J. Trust and distrust: New relationships and realities. Academy of Management Review, Volume 23, pp. 438-458.

Marshall, C. \& Rossman, G. B., 2016. Designing Qualitative Research. 6th ed. Singapore: Sage Publications.

Mayer, R. C., Davis, J. H. \& Schoorman, D. F., 1995. An Integrative Model of Organizational Trust. The Academy of Management Review, 20(3), pp. 709-734.

Mayer, R. C. \& Gavin, M. B., 2005. Trust in management and performance: Who minds the shop while the employees watch the boss?. Academy of Management Journal, Volume 48, pp. 874-888.

MacKenzie, S., Podsakoff, P. \& Rich, G., 2001. Transformational and transactional leadership and salesperson performance. Journal of the Academy of Marketing Science, Volume 29, p. 115-134.

McAllister, D. J., 1995. Affect and cognitive based trust as foundations for interpersonal cooperation in organisations. Academy of Management Journal, 38(1), pp. 24-60.

Moustakas, C. E., 1994. Phenomenological research methods. Thousand Oaks, California: Sage.

Palinkas, L. A. et al., 2015. Purposeful Sampling for Qualitative Data Collection and Analysis in Mixed Method Implementation Research. Administration and Policy in Mental Health and Mental Health Services Research, 42(5), pp. 533-544.

QSR International, 2014. Nvivo10 for Windows - Getting Started, s.I.: QSR International Pty Ltd.

Rich, G., 1997. The sales manager as a role model: Effects of trust, job satisfaction and performance of sales-people. Journal of the Academy of Marketing Science, Volume 25, p. 319-328.

Salazar, N., 2006. Applying the Deming philosophy to the safety system. Professional Safety, pp. 52-57.

Scholefield, M., 2000. Trust, Cambridge: The Relationship Foundation. 
Schoorman, F. D., Mayer, R. C. \& Davis, J. H., 2007. An integrative model of organizational trust: Past, present, and future. Academy of Management Review, 32(2), pp. 344-354.

Shearn, P., 2004. Workforce Participation in the Management of Occupational Health \& Safety, Broad Lane, Sheffield: HSL.

Tharaldsen, J. E., Mearns, K. J. \& Knudsen, K., 2010. Perspectives on safety: The impact of group membership, work factors and trust on safety performance in UK and Norwegian drilling company employees. Safety Science, Volume 48, p. 1062-1072.

Wollard, K. K. \& Shuck, B., 2011. Antecedents to employee engagement: a structured review of the literature. Advances in Developing Human Resources, 13(4), pp. 429-446. 